\title{
Pemanfaatan Augmented Reality Sebagai Media Pembelajaran Pengenalan Warna Objek 3D Kepada Anak Usia Dini Berbasis Android
}

\author{
Jemmy Gunawan \\ Program Studi Teknik Informatika \\ Institut Informatika Indonesia \\ jemzgunz@gmail.com
}

\author{
Timothy John Pattiasina \\ Program Studi Sistem Informasi \\ Institut Informatika Indonesia \\ temmy@ikado.ac.id
}

\author{
Edwin Meinardi Trianto \\ Program Studi Manajemen Informatika \\ Institut Informatika Indonesia \\ edwin@ikado.ac.id
}

\begin{abstract}
Abstrak-Perkembangan teknologi telah mengubah cara pengerjaan suatu pekerjaan dari cara konvensional menjadi cara yang lebih praktis. Dengan hadirnya teknologi augmented reality, proses pembelajaran mewarnai untuk anak usia dini menjadi lebih efektif. Pembuatan aplikasi "Mari Mewarnai" menggunakan program unity dengan Framework Vuforia untuk menerapkan teknologi augmented reality. Penerapan augmented reality membutuhkan objek gambar yang digunakan sebagai image target untuk penyesuaian dengan kriteria, jenis kamera yang digunakan, serta jarak kamera terhadap image target. Pada aplikasi "Mari Mewarnai”, setiap objek tiga dimensi yang digunakan telah melalui proses perubahan agar material dari objek tiga dimensi dapat berubah sesuai dengan image target yang terdapat pada kertas gambar. Dengan pembuatan aplikasi "Mari Mewarnai" ini, anak usia dini dapat mewarnai objek dengan baik karena dapat melihat warna asli dari setiap objek tiga dimensi yang ada.

Kata Kunci : Augmented Reality, Image Target, Mewarnai, Objek 3D, Android, Unity, Vuforia.
\end{abstract}

\section{PENDAHULUAN}

Augmented reality merupakan teknologi yang sedang populer di dunia yang memproyeksikan benda dua dimensi ataupun tiga dimensi ke dalam sebuah lingkungan nyata [1]. Perkembangan augmented reality sangatlah pesat karena teknologi yang dihadirkan dapat memvisualisasikan objek maya yang telah dirancang untuk ditampilkan sehingga terlihat tampak nyata. Selain menghadirkan inovasi baru dalam pengaplikasiannya, augmented reality juga menghadirkan dimensi baru yaitu melakukan deteksi objek yang sudah ditentukan terlebih dahulu serta mengijinkan pengguna melakukan interaksi terhadap aplikasi tersebut.

Masa anak-anak merupakan awal dari kreativitas anak, dimana kreativitas anak berawal dari aktivitas bermain. Melakukan kegiatan yang menyenangkan akan menyebabkan kreativitas anak semakin berkembang. Dimana pendidikan seni pada anak hanya terlihat seperti bermain-main saja. Tetapi perlu diketahui bahwa melalui pendidikan seni dapat meningkatkan kreativitas anak, karena anak akan bereksplorasi mengenai hal-hal baru maupun hal-hal yang sudah diketahui, khususnya pendidikan seni mewarnai. Melalui kegiatan mewarnai siswa, siswa dapat mengekspresikan berbagai imajinasi yang ada dalam pikirannya, dan juga dari hasil pewarnaan yang dihasilkan juga dapat menunjukkan tingkat kreativitas anak.

Berdasarkan latar belakang tersebut, penulis tertarik untuk mendalami pembuatan aplikasi pembelajaran tentang mewarnai yang menyenangkan dengan menggunakan teknologi augmented reality yang dipresentasikan melalui mobile device. Adapun rentang usia dari pengguna aplikasi, dalam hal ini anak usia dini adalah 3 tahun sampai dengan 4 tahun.

\section{METODOLOGI PENELITIAN}

\section{A. Augmented Reality}

Augmented Reality merupakan teknologi yang menggabungkan benda maya dua dimensi dan ataupun tiga dimensi ke dalam sebuah lingkungan nyata tiga dimensi lalu memproyeksikan benda-benda maya tersebut secara real-time. Tiga dimensi biasa disingkat $3 \mathrm{D}$ atau disebut ruang dari benda yang memiliki panjang, lebar, dan tinggi. Istilah ini biasanya digunakan dalam bidang seni, animasi, komputer dan matematika. Benda-benda maya menampilkan informasi berupa label maupun objek virtual yang hanya dapat dilihat dengan kamera handphone maupun dengan komputer. Sistem dalam Augmented Reality bekerja dengan menganalisa secara real-time objek yang ditangkap dalam kamera [2].

\section{B. Unity $3 D$}

Unity 3D adalah salah satu software yang bagus untuk mengembangkan game tiga dimensi, dimana unity merupakan software yang interaktif dan dapat juga digunakan untuk membuat animasi tiga dimensi. Unity lebih tepat dijelaskan sebagai salah satu software untuk mengembangkan video game atau disebut juga game engine, dikarenakan unity menggunakan grafis yang cukup tinggi untuk pengembangan aplikasi tiga dimensi. 


\section{Qualcomm Vuforia}

Qualcomm Vuforia adalah Augmented Reality Software Development Kit (SDK) yang di gunakan pada perangkat mobile untuk pembuatan aplikasi augmented reality [3]. SDK ini menggunakan teknologi computer vision untuk mengenali dan melacak gambar target dan objek 3D yang sederhana secara real time. Dengan kemampuan ini, memungkinkan para developer untuk membuat posisi dan orientasi objek virtual seperti model 3D dan media-media lainnya yang berkaitan dengan dunia nyata dapat dilihat melalui kamera dari perangkat mobile.

\section{Unity 3D}

Unity merupakan salah satu dari game engine untuk membuat bentuk objek 3D pada video game [4]. Dengan menggunakan software ini, developer dapat membuat game dengan lebih mudah dan cepat. Pengembangan Unity 3D ini dapat berjalan di Windows dan Mac OS, sedangkan permainan yang dibuat dapat digunakan di berbagai platform seperti Windows, Mac, Xbox 360, Playstation 3, Nintendo Wii, iPad, iPhone, dan Android.

\section{E. Teori Warna}

Warna adalah salah satu elemen visual yang dapat dengan mudah menarik perhatian seseorang [5]. Betapa sepinya dunia desain grafis jika tanpa kehadiran warna. Namun demikian, perlu berhati-hati dalam penggunaan warna. Apabila pemakaian warna kurang tepat maka dapat merusak citra, mengurangi nilai, keterbacaan, dan bahkan dapat menghilangkan gairah baca. Warna dapat membantu menciptakan mood dan membuat teks lebih berbicara.

\section{HASIL DAN PEMBAHASAN}

Sebelum dilakukan implementasi program, perlu dilakukan analisa dan desain sistem untuk mempermudah implementasi program karena sebagai acuan untuk menghasilkan program yang baik.

\section{A. Use Case Diagram}

Use Case Diagram pada aplikasi menjelaskan bagaimana jalannya sebuah aplikasi yang melibatkan 1 aktor dalam kegiatannya [6]. Untuk aplikasi yang akan dirancang, dibutuhkan 1 aktor utama yaitu anak usia dini serta 7 use case guna menunjukkan aktifitas yang dilakukan oleh actor utama pada aplikasi. Adapun use case yang dimaksud terdiri atas use case memilih menu petunjuk, memilih menu tentang, memilih tombol suara, memilih menu mulai, mengarahkan mobile device ke gambar, menampilkan objek 3D beserta keterangan dan mewarnai gambar pada kertas. Berikut merupakan penjabaran dari interaksi apa saja yang terjadi dalam aplikasi.

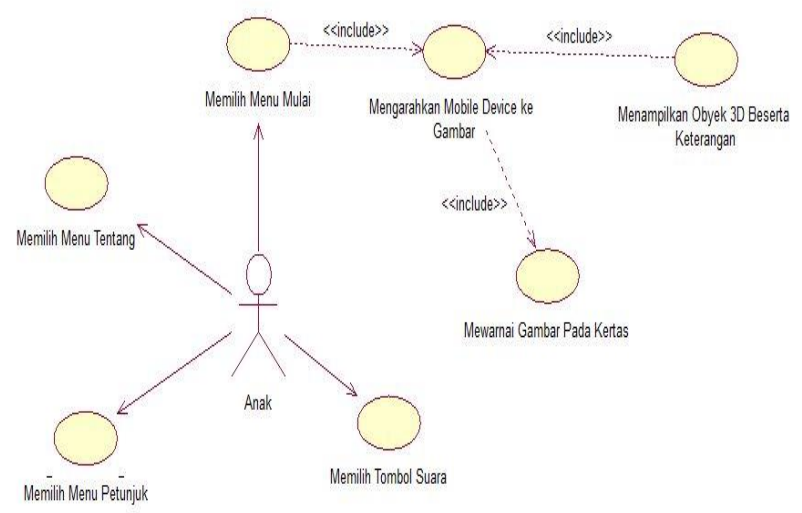

Gambar 1. Use Case Diagram Aplikasi Mari Mewarnai

Pada use case diagram aplikasi mari mewarnai ini diberikan gambaran singkat mengenai apa saja yang dapat dilakukan oleh pengguna aplikasi, dalam hal ini anak usia dini ketika mulai menjalankan aplikasi. Ketika pengguna masuk ke halaman utama aplikasi, pengguna dapat segera memilih menu mulai atau melihat halaman tentang dan petunjuk. Saat memilih menu mulai, aplikasi akan secara otomatis membuka kamera agar dapat langsung diarahkan pada kertas gambar yang telah diberi image target. Jika image target pada kertas sesuai dengan yang ada pada aplikasi, maka pada layar mobile device akan menampilkan objek berupa tiga dimensi sesuai dengan apa yang ada pada kertas.

\section{B. Activity Diagram}

Diagram ini mengandung aktivitas, pilihan tindakan, perulangan dan hasil dari aktivitas yang digunakan untuk memperjelas use case diagram yang sudah dibuat sebelumnya. Berikut adalah activity diagram dari aplikasi mari mewarnai".

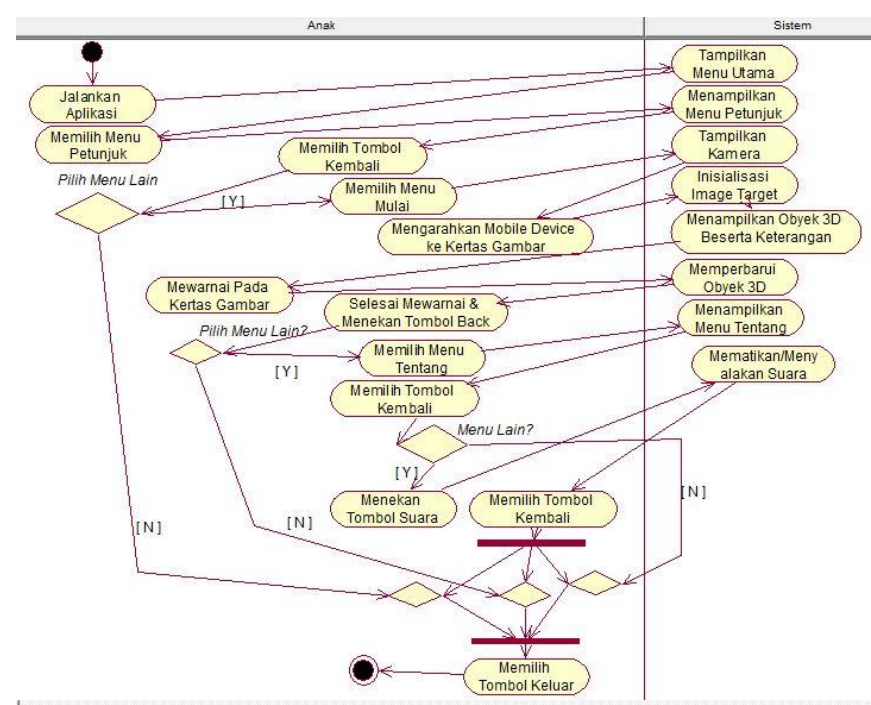

Gambar 2. Activity Diagram Aplikasi Mari Mewarnai 
Activity diagram aplikasi mari mewarnai ini menjelaskan tentang alur interaksi antara pengguna aplikasi dengan sistem, mulai dari awal sampai dengan akhir dari penggunaan aplikasi. Pada saat pengguna menjalankan aplikasi, menu utama akan tampil, lalu akan terdapat beberapa menu pilihan, yaitu menu tentang, petunjuk, mulai dan juga tombol suara apabila pengguna ingin mematikan atau menyalakan suara. Pada gambar tersebut juga diperlihatkan interaksi pengguna dengan sistem dimana saat memilih menu mulai maka akan dilanjutkan dengan runtutan interaksi, dimulai dari pengenalan image target hingga aplikasi dapat menampilkan objek tiga dimensi beserta informasi terkait objek tersebut.

\section{Sequence Diagram}

Berikut adalah sequence diagram dari aplikasi mari mewarnai.

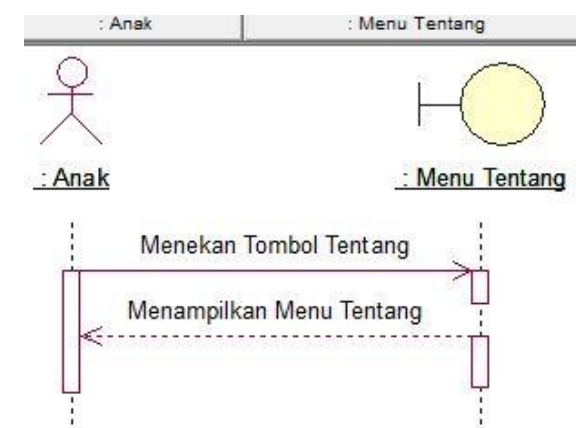

Gambar 3. Sequence Diagram Menu Tentang

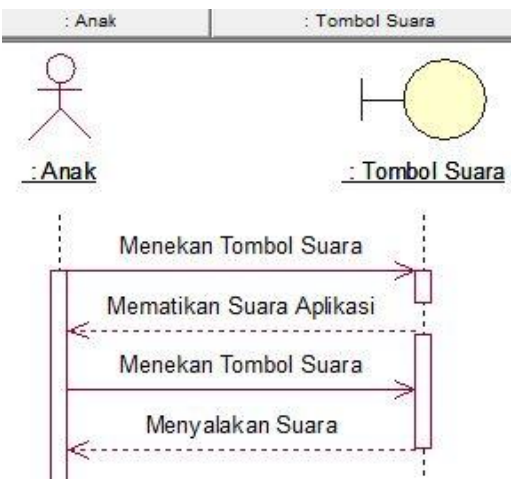

Gambar 4. Sequence Diagram Memilih Tombol Suara

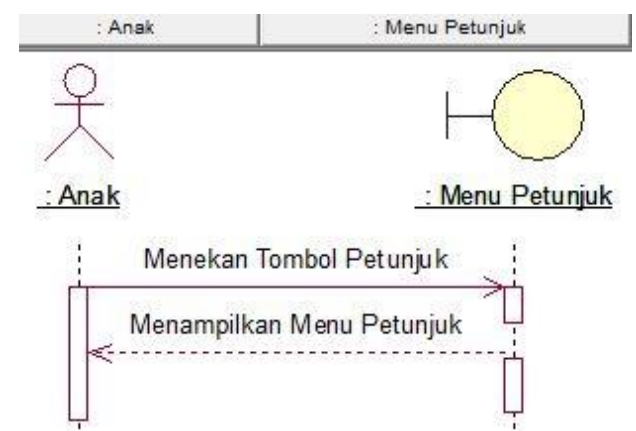

Gambar 5. Sequence Diagram Memilih Menu Petunjuk

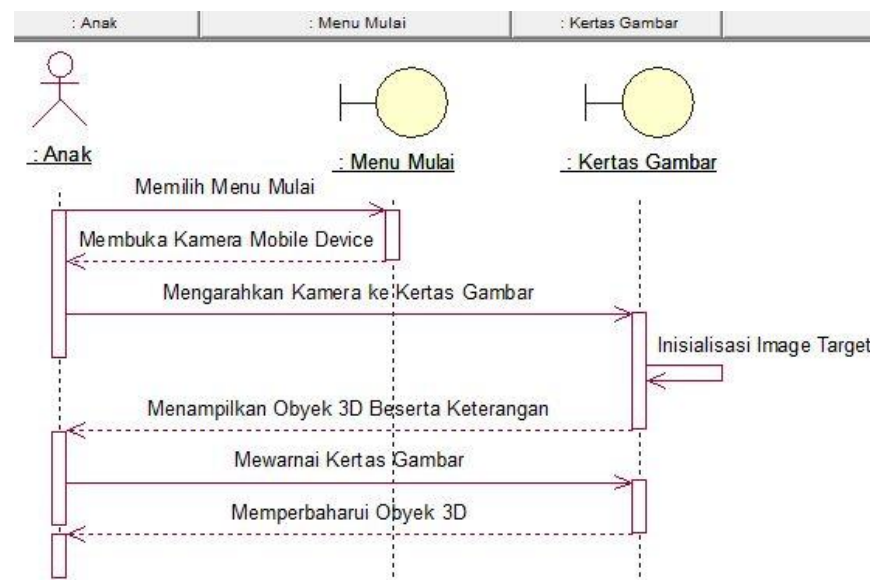

Gambar 6. Sequence Diagram Memilih Menu Mulai

D. Pemanfaatan Augmented Reality

Augmented reality merupakan bagian utama dari pembuatan aplikasi mari mewarnai ini. Pemanfataan augmented reality pada aplikasi ini terletak pada bagaimana sistem mengenali kertas gambar sebagai image target dan juga perubahan warna yang dilakukan sistem kepada objek tiga dimensi apabila kertas gambar telah diwarnai oleh pengguna aplikasi.

- Deteksi Image Target

Untuk dapat mendeteksi apakah objek tersebut merupakan image target yang ditentukan atau tidak, diperlukan media perekam yaitu kamera pada mobile device. Adapun urutan aktivitas yang dilakukan seperti terlihat pada gambar berikut.

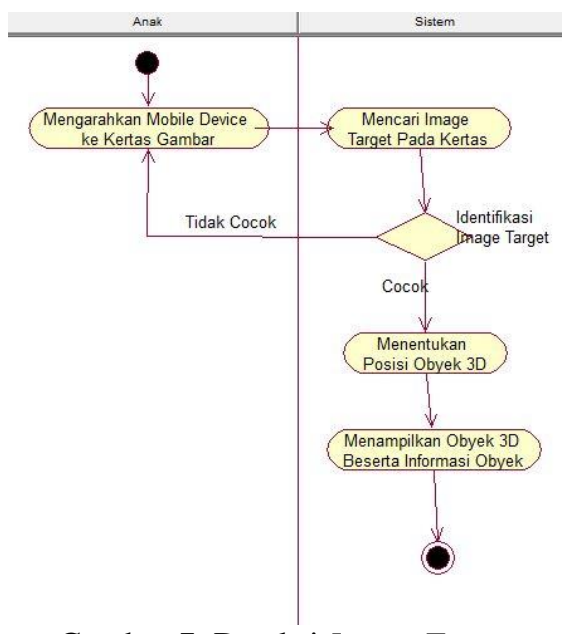

Gambar 7. Deteksi Image Target

Dapat dilihat pada gambar 7, kamera yang terdapat pada mobile device akan menangkap objek yang terpantau oleh lensa. Hasilnya akan dikirim ke dalam aplikasi pada mobile device untuk diproses apakah objek yang terpantau merupakan image target atau bukan.

- Cara Kerja Pewarnaan Texture 3D

Texture pada objek tiga dimensi merupakan pola utama yang membungkus objek tersebut agar objek yang ada dapat dibuat lebih menarik dengan merubah warna 
ataupun tampilan dari objek tiga dimensi. Urutan aktifitas perubahan texture yang dimaksud pada objek 3 dimensi dapat dijelaskan pada gambar dibawah ini.

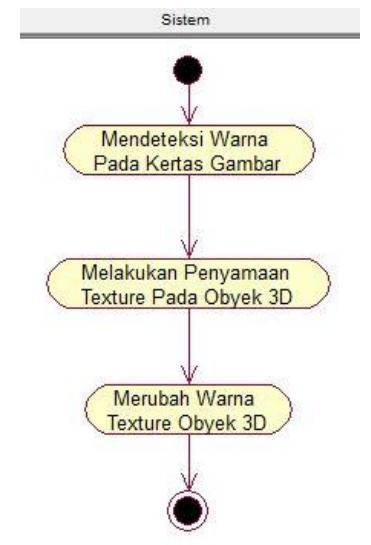

Gambar 8. Cara Kerja Pewarnaan Texture 3D

\section{E. UV Mapping}

Dalam objek tiga dimensi, terdapat banyak komponen penting yang tercantum dalam objek tersebut, salah satunya adalah texture. Texture dalam objek tiga dimensi digunakan untuk merubah tampilan luar dari sebuah objek. Penggunaan texture pada sebuah objek tentunya perlu suatu pemetaan terlebih dahulu agar texture yang digunakan dalam objek tersebut dapat tersusun dengan baik.

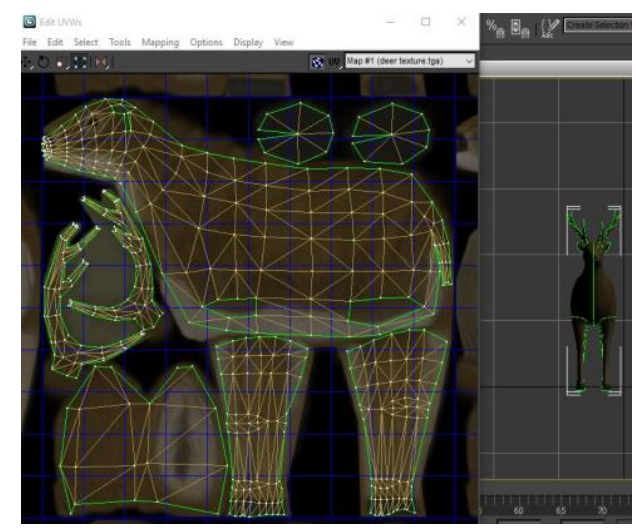

Gambar 9. Pemetaan Texture Objek 3D

Pada gambar 9 merupakan tampilan dari pemetaan texture pada suatu objek yang telah tersusun rapi. Setiap bagian dari objek tiga dimensi telah dipecah masing-masing dan disesuaikan dengan texture yang ada. Pemetaan texture dilakukan agar setiap bagian dari objek tiga dimensi memiliki warna yang sesuai dengan texture yang telah disiapkan. Dengan adanya pemetaan texture yang baik, maka penyamaan texture pada kertas gambar dan objek tiga dimensi menjadi lebih mudah. Berikut adalah contoh pengenalan kertas gambar sebagai image target dengan pemetaan texture 3 dimensi yang baik.

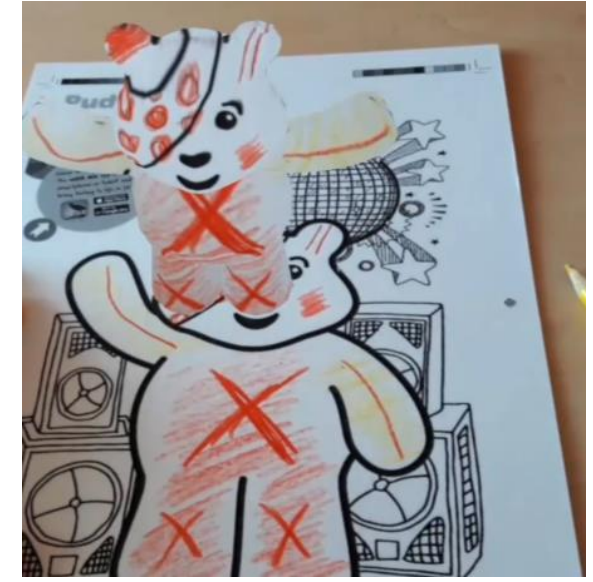

Gambar 10. Pengenalan Image Target Pada Kertas Gambar

Dapat juga dilihat dalam gambar 10 bagaimana perubahan warna yang terjadi pada objek 3 dimensi terjadi saat pengguna mulai melakukan pewarnaan pada kertas gambar.

\section{F. User Interface}

Pada sub bab ini akan ditunjukkan tampilan antar muka dari aplikasi mari mewarnai, dimana user dapat berinteraksi didalamnya. Berikut adalah desain interface dari aplikasi mari mewarnai.

a) Menu Utama

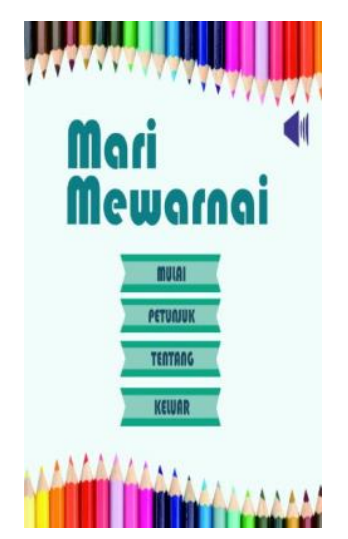

Gambar 11. Menu Utama

Di dalam menu utama aplikasi mari mewarnai terdapat 5 buah tombol yaitu tombol mulai, petunjuk, tentang, keluar, dan tombol suara. Bila pengguna menekan tombol mulai, maka aplikasi akan langsung membuka kamera dari mobile device. Bila pengguna menekan tombol petunjuk, maka akan ditampilkan petunjuk penggunaan aplikasi. Bila pengguna menekan tombol tentang, maka akan ditampilkan dengan menu yang menjelaskan lebih lanjut mengenai orang yang berperan dalam pembuatan aplikasi ini. Bila pengguna menekan tombol keluar maka secara otomatis aplikasi akan tertutup. Apabila user menekan tombol suara, maka seluruh suara dari aplikasi akan di nonaktifkan. 
b) Menu Mulai

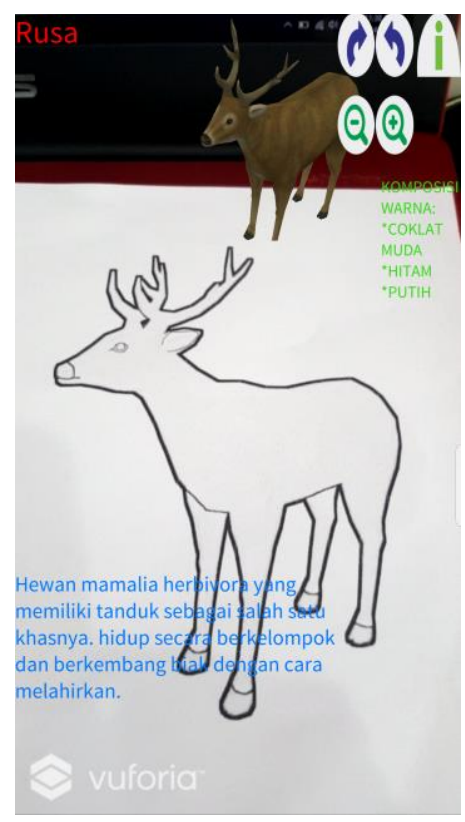

Gambar 12. Menu Mulai dengan Tombol Informasi

Menu mulai merupakan menu yang digunakan oleh pengguna aplikasi untuk mulai mewarnai objek. Pada saat pengguna menekan tombol mulai, maka sistem akan secara otomatis membuka kamera dari mobile device lalu pengguna dapat mengarahkan kamera ke kertas gambar yang telah memiliki image target yang sesuai dengan aplikasi. Gambar 12 merupakan tampilan saat kamera telah mendeteksi image target yang sesuai dengan sistem. Sistem akan memunculkan objek tiga dimensi yang sesuai dengan kertas gambar beserta dengan nama dari objek beserta sedikit informasi yang terkait dengan objek. Terdapat tombol informasi dibagian kanan atas yang berguna untuk menampilkan objek tiga dimensi yang asli beserta dengan warna yang digunakan pada objek tersebut.

c) Menu Petunjuk

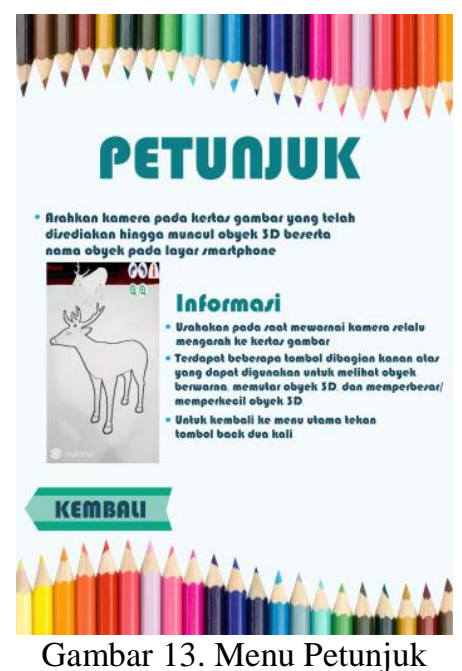

Menu petunjuk terdapat pada pilihan di menu utama. Menu ini dapat diakses apabila pengguna masih belum memahami cara penggunaan dari aplikasi mari mewarnai. Menu ini disediakan dengan tujuan untuk memberikan arahan serta petunjuk singkat cara penggunaan aplikasi dan terdapat informasi bagi penguna untuk mendukung kinerja pemakaian aplikasi mari mewarnai.

d) Menu Tentang
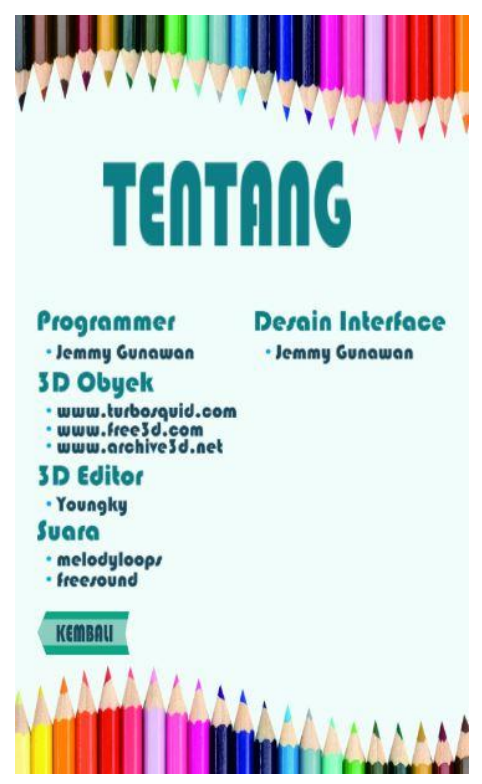

Gambar 14. Menu Tentang

Menu tentang berisi keterangan nama-nama pihak yang berperan dalam pembuatan aplikasi mari mewarnai. Terdapat daftar nama untuk programmer, sumber objek 3D, 3D editor, suara, dan desain interface. Apabila user menekan tombol kembali, user akan dikembalikan ke menu utama.

\section{G. Pengujian \\ a) Completing a Transaction}

Pada bagian ini penulis melakukan pengujian dengan menggunakan metode yang pertama yaitu completing a transaction, disini penulis akan memberikan beberapa skenario uji coba kepada pengguna dari aplikasi, dalam hal ini kepada 7 orang anak usia dini (rentang usia 3 tahun sampai dengan 4 tahun) saat mulai menggunakan aplikasi mari mewarnai ini. Ketujuh anak usia dini yang mencoba aplikasi ini sedang menempuh jenjang Pendidikan Anak Usia Dini (PAUD) dan rata-rata cukup mahir menggunakan mobile device. Hal ini dikarenakan beberapa materi yang diajarkan kepada mereka pada saat mengenyam pendidikan di PAUD juga menggunakan mobile device sebagai sarana pembelajarannya. 
Tabel 1. Skenario Pengujian

\begin{tabular}{cll}
\hline No & \multicolumn{1}{c}{ Task } & \multicolumn{1}{c}{ Keterangan } \\
1. & $\begin{array}{l}\text { Mewarnai Dengan } \\
\text { Melihat Kertas } \\
\text { Gambar }\end{array}$ & $\begin{array}{l}\text { Pengguna mewarnai } \\
\text { gambar dengan melihat } \\
\text { pada kertas secara langsung }\end{array}$ \\
\hline 2. & $\begin{array}{l}\text { Menampilkan } \\
\text { Informasi Objek 3D }\end{array}$ & $\begin{array}{l}\text { Pengguna menekan tombol } \\
\text { informasi setelah kamera } \\
\text { mendeteksi image target }\end{array}$ \\
\hline & $\begin{array}{l}\text { Mewarnai Gambar } \\
\text { Sesuai Contoh } \\
\text { Warna }\end{array}$ & $\begin{array}{l}\text { Pengguna mewarnai kertas } \\
\text { gambar dengan warna yang } \\
\text { sesuai pada objek tiga } \\
\text { dimensi }\end{array}$ \\
\hline 4. & Memutar Objek 3D & $\begin{array}{l}\text { Pengguna menekan tombol } \\
\text { rotasi setelah kamera } \\
\text { mendeteksi image target }\end{array}$ \\
\hline & Memperbesar/Mem- & $\begin{array}{l}\text { Pengguna menekan tombol } \\
\text { perbesar/ perkecil setelah } \\
\text { kamea mendeteksi image } \\
\text { target }\end{array}$ \\
\hline
\end{tabular}

- Hasil Perhitungan Skenario Pengujian

Dengan menggunakan skenario pada tabel 1 skenario pengujian, dilakukan pengujian terhadap 7 orang pengguna dengan karakterisik yang sama yaitu anak usia dini yang berusia tiga sampai empat tahun. Dengan pengujian terhadap 7 orang pengguna tadi, penulis telah melakukan perhitungan untuk mengambil berapa banyak pengguna yang telah menyelesaikan skenario yang telah diberikan dengan benar. Adapun rumus yang dipakai dalam perhitungan hasil penyelesaian skenario adalah:

$$
\frac{\Sigma \text { pengguna menjawab sesuai }}{\Sigma \text { pengguna }} \times 100 \%
$$

Hasil perhitungan tersebut dapat dilihat pada tabel berikut:

Tabel 2. Hasil Skenario Pengujian

\begin{tabular}{clc}
\hline No & \multicolumn{1}{c}{ Skenario } & Persentase \\
\hline 1. & $\begin{array}{l}\text { Mewarnai Dengan Melihat Kertas } \\
\text { Gambar }\end{array}$ & $100 \%$ \\
\hline 2. & Menampilkan Informasi Objek 3D & $71 \%$ \\
\hline 3. & $\begin{array}{l}\text { Mewarnai Gambar Sesuai Contoh } \\
\text { Warna }\end{array}$ & $100 \%$ \\
\hline 4. & Memutar Objek 3D & $0 \%$ \\
\hline 5. & $\begin{array}{l}\text { Memperbesar/Memperkecil Objek } \\
\text { 3D }\end{array}$ & $0 \%$ \\
\hline
\end{tabular}

Berdasarkan hasil pengujian yang telah dihitung, pada skenario 1 dan 3 dapat disimpulkan bahwa aplikasi yang dibuat dapat memberikan informasi yang berguna untuk pengguna. Hal ini didasari atas adanya fitur pada aplikasi yang dapat menampilkan warna asli dari objek tiga dimensi dengan memanfaatkan teknologi augmented reality, dimana pada saat pemakaian aplikasi pengguna dapat langsung mencocokkan pensil warna yang akan digunakan untuk mewarnai dengan melihat warna asli pada objek yang menjadi image target.
Sedangkan hasil perhitungan pada skenario 2 menunjukkan bahwa tidak semua anak memanfaatkan fitur informasi dari objek 3 dimensi yang ditampilkan. Hal ini disebabkan anakanak tersebut lebih fokus dalam mengenal warna yang ditampilkan melalui objek dan menuangkannya pada kertas gambar mereka masing-masing, sehingga fitur informasi tidak terlalu diperhatikan.

Namun demikian, dari hasil pengujian pada skenario 4 dan 5 menunjukkan bahwa ada keterbatasan pemahaman dan kemampuan yang dimiliki anak-anak usia dini, dimana mereka masih belum bisa memahami fitur-fitur yang membutuhkan kecakapan motorik seperti fitur scaling object serta fitur rotating object. Hal tersebut disebabkan kecenderungan dari anak-anak, khususnya pada rentang usia 3 sampai dengan 4 tahun untuk lebih fokus pada satu hal yang menarik perhatian daripada hal-hal lainnya yang kurang menarik perhatian mereka.

\section{b) Pengujian Kualitas Kamera}

Pengujian terhadap kamera yang berbeda dapat menghasilkan informasi yang berguna dalam pemilihan kamera yang digunakan pada aplikasi mari mewarnai yang memanfaatkan teknologi augmented reality.

Tabel 3. Spesifikasi Kamera

\begin{tabular}{|c|c|c|c|}
\hline No & $\begin{array}{c}\text { Merk } \\
\text { Smartphone }\end{array}$ & $\begin{array}{l}\text { Resolusi } \\
\text { Kamera }\end{array}$ & $\begin{array}{c}\text { Auto Focus } \\
\text { (AF) }\end{array}$ \\
\hline 1 & Evercoss AT1C & 3 Megapixel & $x$ \\
\hline 2 & $\begin{array}{l}\text { Samsung Galaxy } \\
\text { Note II }\end{array}$ & 8 Megapixel & $\checkmark$ \\
\hline 3 & BMXC K107 & 5 Megapixel & $\checkmark$ \\
\hline 4 & $\begin{array}{l}\text { Lenovo Vibe K4 } \\
\text { Note }\end{array}$ & $\begin{array}{l}13 \\
\text { Megapixel } \\
\end{array}$ & $\checkmark$ \\
\hline 5 & $\begin{array}{l}\text { Samsung Galaxy } \\
\text { S6 Edge }\end{array}$ & $\begin{array}{l}16 \\
\text { Megapixel }\end{array}$ & $\checkmark$ \\
\hline
\end{tabular}

\section{c) Pengujian Jarak Kamera}

Jarak kamera terhadap image target sagat mempengaruhi stabilitas pengenalan image target. Diperlukan jarak yang cocok untuk mendapatkan hasil yang optimal, agar pada saat mewarnai pengguna dapat melihat objek tiga dimensi pada smartphone dengan baik. Maka dari hasil analisa tersebut, pencarian jarak optimal sangat diperlukan guna menjalankan aplikasi mari mewarnai dengan baik.

Tabel 4. Hasil Uji Coba Jarak Kamera

\begin{tabular}{clc}
\hline No & \multicolumn{1}{c}{ Smartphone } & $\begin{array}{c}\text { Jarak Kamera } \\
\text { Terhadap } \\
\text { Image Target }\end{array}$ \\
\hline 1 & Evercoss AT1C & $16 \mathrm{~cm} \mathrm{~s} / \mathrm{d} 60 \mathrm{~cm}$ \\
\hline 2 & Samsung Galaxy Note II & $10 \mathrm{~cm} \mathrm{~s} / \mathrm{d} 45 \mathrm{~cm}$ \\
\hline 3 & BMXC K107 & $14 \mathrm{~cm} \mathrm{~s} / \mathrm{d} 69 \mathrm{~cm}$ \\
\hline 4 & Lenovo Vibe K4 Note & $10 \mathrm{~cm} \mathrm{~s} / \mathrm{d} 69 \mathrm{~cm}$ \\
\hline 5 & Samsung Galaxy S6 Edge & $10 \mathrm{~cm} \mathrm{~s} / \mathrm{d} 70 \mathrm{~cm}$ \\
\hline
\end{tabular}




\section{KESIMPULAN DAN SARAN}

A. Kesimpulan

Dari penelitian yang telah dilakukan, didapatkan beberapa kesimpulan yang dapat diambil dari proses pembuatan aplikasi mari mewarnai yang memanfaatkan teknologi augmented reality, antara lain:

- Dengan memanfaatkan teknologi augmented reality, anakanak usia dini dapat lebih mudah untuk mengenali warna dari objek tiga dimensi dengan cara melihat warna asli dari objek yang akan diwarnai dalam wujud 3 dimensi yang melalui perangkat mobile device.

- Objek tiga dimensi dapat divisualisasikan dalam perangkat smartphone saat kamera mendeteksi kertas gambar yang telah dijadikan sebagai image target.

- Fitur rotating dan scaling objek tiga dimensi masih belum dapat digunakan secara maksimal oleh anak usia dini, karena kecenderungan anak-anak untuk lebih fokus pada kegiatan mewarnai objek daripada menggunakan kedua fitur tersebut.

B. Saran

Saran yang dapat diberikan dari aplikasi "Mari Mewarnai" yang memanfatkan teknologi augmened reality lebih lanjut adalah:

- Pengenalan pola image target oleh kamera sering terjadi gangguan yang diakibatkan karena outline dari gambar pada kertas tertutupi oleh warna yang digunakan anakanak pada saat mewarnai. Perlu mempertegas outline dari setiap gambar agar aplikasi dapat menangkap image target dengan baik.

- Penambahan animasi dari setiap objek pada aplikasi agar anak-anak usia dini dapat lebih tertarik untuk mewarnai.

\section{REFERENSI}

[1] Efendi, Y. (2016). Penerapan Teknologi AR (Augmented Reality) Pada Pembelajaran Energi Angin Kelas IV SD Di Rumah Pintar Al-Barokah. Jurnal Sistem Informasi STTI NIIT I-Tech. Vol. I, No. 9, pp. 29-47.

[2] Rifa, M.. (2014). Penerapan Teknologi Augmented Reality Pada Aplikasi Katalog Rumah Berbasis Android. Jurnal Teknik Informatika Universitas Muria Kudus. Vol. I, No. 1.

[3] Nazruddin, S. (2014). Android Pemrograman Aplikasi Mobile Smartphone. INFORMATIKA.

[4] Raharja, T.M. (2013). Analisis Penerapan Augmented Reality Dalam Perancangan Sistem Katalog Design Perumahan CV. Raft Origin. Jurnal Ilmu Komputer Universitas Sumatera Utara.

[5] Kusrianto, A. (2015). Desain Komunikasi Visual. Yogyakarta: Penerbit Andi.

[6] Shalahuddin, M., dan Rosa, A.S. (2015). Rekayasa Perangkat Lunak Terstruktur dan Berorientasi Objek. Bandung: Informatika. 